\title{
3,4-DIMETHYL-2,5-HEXANEDIONE IMPAIRS THE AXONAL TRANSPORT OF NEUROFILAMENT PROTEINS ${ }^{1}$
}

\author{
JOHN W. GRIFFIN, ${ }^{*, 2}$ D. CARTER ANTHONY, $\ddagger$ KENNETH E. FAHNESTOCK,* \\ PAUL N. HOFFMAN,§ AND DOYLE G. GRAHAM $\ddagger$
}

*Neuromuscular Laboratories, Department of Neurology and Department of Neuroscience, Johns Hopkins University School of Medicine, Baltimore, Maryland 21205, $\ddagger$ Department of Pathology, Duke University Medical Center,

Durham, North Carolina 27710, and §Department of Ophthalmology, Johns Hopkins University School of Medicine, Baltimore, Maryland 21205

Received August 5, 1983; Revised January 10, 1984; Accepted January 11, 1984

\begin{abstract}
Accumulations of neurofilaments are observed in a variety of neurological disorders, and their pathogenesis is a fundamental problem of neuropathology. 2,5-Hexanedione (HD) neurotoxicity provides an extensively studied model of axonal neurofibrillary changes in which the pathogenetic mechanisms have been conjectural. Chronic exposure to HD results in neurofilament-filled swellings in the distal regions of large axons of exposed humans and experimental animals. In this report we describe the changes produced by a potent analogue of HD, 3,4-dimethyl-2,5-hexanedione (DMHD), in slow axonal transport in the rat sciatic motor axons. Young rats received $0.6 \mathrm{mmol} / \mathrm{kg}$ of DMHD for 5 days before $\left[{ }^{35} \mathrm{~S}\right]$ methionine was injected into the lumbar ventral horns. Slow axonal transport of the neurofilament proteins, tubulin, and selected slow component $b(\mathrm{SCb})$ proteins in DMHDtreated animals was compared to the profiles found in age-matched control animals. DMHD administration reduced the rate of transport of the neurofilament proteins 75 to $90 \%$, while tubulin and the $\mathrm{SCb}$ proteins were only modestly retarded. No alterations in electrophoretic mobilities of slowly transported proteins were found, nor were any proteins accelerated in transport. These findings were systematically compared to the changes produced by administration of $\beta, \beta^{\prime}$-imminodipropionitrile (IDPN) $(2.0 \mathrm{gm} / \mathrm{kg}$, i.p.), an agent known to impair neurofilament transport. Although slightly less severe, the changes produced by DMHD were nearly identical to those of IDPN. In correlative morphological studies, the neurofilamentous changes were also comparable. The results indicate that DMHD and IDPN share the capacity to interfere selectively with neurofilament transport and thereby share pathogenetic mechanisms. DMHD provides a new agent for exploration of the organization and transport of the neuronal cytoskeleton.
\end{abstract}

Neurofilament accumulations are pathological hallmarks of a variety of toxic, degenerative, and heritable neurological diseases, and their pathogenesis represents a fundamental problem in neuropathology (for review see Wisniewski and Soifer, 1979; Selkoe, 1982). Focal accumulations of neurofilaments could in theory be due

\footnotetext{
${ }^{1}$ This work was supported in part by National Institute of Neurological and Communicative Disorders and Stroke Grants NS14784 and NS15721 and National Institute of Environmental Health Services Grant ES02611. Dr. Griffin is the recipient of National Institutes of Health-National Institute of Neurological and Communicative Disorders and Stroke Research Career Development Award 00450. P. N. H. is the recipient of fellowships from the Alfred P. Sloan Foundation and the George L. and John A. Hartford Foundation.

${ }^{2}$ To whom correspondence should be addressed, at Meyer Building, Room 5-119, Johns Hopkins University School of Medicine, 600 North Wolfe Street, Baltimore, MD 21205.
}

to increased synthesis, increased polymerization of sol uble subunits, decreased degradation, or altered intrace! lular distribution. In neurons, the site of protein synthesis is restricted to the nerve cell body. For this reason, experimental models which produce neurofilament ac cumulations primarily within axons provide the investigator with systems in which the site of neurofilament deposition is remote from the site of synthesis.

Hexacarbon neurotoxicity provides an extensively studied model of neurofibrillary changes within the axon (for review see Spencer et al., 1980; Allen, 1980; Griflin 1981). Major clinical outbreaks of peripheral neuropathy have occurred in "glue sniffers" exposed to $n$-hexane (Shirabe et al., 1974; Korobkin et al., 1975) and in industrial workers exposed to $n$-hexane (Ishii et al., 1972) or methyl $n$-butyl ketone (Mendell et al., 1974; Allen, 1980). The agent responsible for the neurotoxicity is the 
common metabolite, 2,5-hexanedione (HD) (DiVincenzo et al., 1976). The characteristic pathological alteration is multifocal accumulations of neurofilaments in large axons, producing the neurofilamentous axonal swellings (Saida et al., 1976; Spencer and Schaumburg, 1977; Cavanagh and Bennetts, 1981). The distal region of the nerve fibers may subsequently undergo Wallerian-like degeneration (Spencer and Schaumburg, 1977). The axonal swellings tend to form in the distal portions of nerve fibers. Recently Graham et al. (1982a) and Anthony et al. $(1983 \mathrm{a}, \mathrm{b}, \mathrm{c})$ have described a more potent analogue of HD, 3,4-dimethyl-2,5-hexanedione (DMHD), in which the swellings develop rapidly and are initially located in the proximal regions of the nerves.

The pathogenesis of the neurofibrillary changes produced by $\mathrm{HD}$ has been conjectural. A defect in slow axonal transport has been widely suspected (Sabri et al., 1979; Graham et al., 1982a; Spencer and Griffin, 1982; Anthony et al., 1983b, c), based in part on the ultrastructural similarities of these swellings to those produced by $\beta, \beta^{\prime}$-iminodipropionitrile (IDPN), an agent known to impair neurofilament transport (Griffin et al., 1978, 1982a; Yokoyama et al., 1980; Papasozomenos et al., 1981). Previous axonal transport studies in HD neuropathy have found defects in fast transport, at least in part related to excessive retention of rapidly transported materials within giant axonal swellings (Mendell et al., 1974; Spencer and Griffin, 1982), but these studies have not addressed the slow transport system.

This report describes a systematic comparison of slow axonal transport in DMHD-treated, IDPN-treated, and normal rats. The transport of the neurofilament proteins, tubulin, and slow component $b$ proteins was individually analyzed, and for comparison the results were expressed as "half-velocities." We paid particular attention to whether any abnormalities found with DMHD might affect neurofilament transport selectively or whether other slow component constituents might also be affected.

\section{Materials and Methods}

Animals. In these studies male Sprague-Dawley rats 3 to 5 weeks of age were used, because previous studies have shown that slow transport in these young rats is much faster than in older rats (Hoffman et al., 1983). This more rapid slow transport shortened the duration of experiments and reduced concern about possible reversibility of changes produced by short-term administration schedules. Correlative morphological studies were undertaken to confirm that using the dosage schedules described below, pathological changes occurred in rats of these ages.

\section{Administration of toxins}

$D M H D$. For 5 of the 7 days before labeling, animals received intraperitoneal injections of DMHD, $0.6 \mathrm{mmol} /$ $\mathrm{kg} /$ day in Ringer's solution. DMHD was synthesized by the dehydrodimerization of 2-butanone using lead dioxide, as described by Wolthius et al. (1963). The product, which distilled between 65 and $70^{\circ} \mathrm{C}$ at $5 \mathrm{~mm} \mathrm{Hg}$, was shown to be 3,4-dimethyl-2,5-hexanedione by its mass spectrum obtained on a Hewlett-Packard 599A GC-MS system, and by the nuclear magnetic resonance spectrum obtained with an IBM NR-80 FT spectrometer. The purity by gas chromatography was $>99 \%$.

$I D P N$. IDPN (Eastman lot A8A) was stored at $-20^{\circ} \mathrm{C}$ in dark bottles. Animals were given injections of $2 \mathrm{gm} /$ $\mathrm{kg}$ intraperitoneally (diluted 5 to 1 in normal saline). In most studies the animals were injected on the day after labeling.

\section{Transport studies}

The techniques followed the methods previously utilized in our laboratory and described fully elsewhere (Griffin et al., 1976, 1981). The precursor solution was $\left[{ }^{35} \mathrm{~S}\right]$ methionine (specific activity 800 to $1200 \mathrm{Ci} / \mathrm{mmol}$, Amersham), concentrated to 80 to $100 \mu \mathrm{Ci} / \mu \mathrm{l}$ in $0.9 \%$ saline. A volume of $10 \mu \mathrm{l}$ was drawn into a micropipette, and $1-\mu l$ aliquots were injected into the lumbar ventral horns which give rise to the L4 and L5 ventral roots. A total of four injections on each side was made (for details of the surgical procedure see Griffin et al., 1976, 1981). Following closure of the surgical wound, the animals were returned to their cages. Control, DMHD, and IDPN groups of animals were killed $2,4,12$, and 21 days after labeling. These animals were all 5 weeks of age at the time of labeling. In addition, control animals were labeled at 3 weeks of age and sacrificed 15 days later; these animals were compared to an animal injected with IDPN the day after labeling.

The nerves were removed with careful attention to harvesting both the L4 and L5 spinal roots. The roots and nerves were then cut into $3-$ or $6-\mathrm{mm}$ segments, and each segment was homogenized in $250 \mu$ l of SDS/urea/ $\beta$-mercaptoethanol, as previously described (Griffin et al., 1978; Hoffman et al., 1983). A 10- $\mu$ l aliquot of the resulting solution was dissolved in Ultrafluor (National Diagnostics) and counted in a Beckman LS 150 liquid scintillation counter. The counts were used to construct plots of the distribution of slowly transported proteins along the nerve. The remainder of each sample was applied as a single track on a polyacrylamide slab gel. The gels (gradient 5 to $17.5 \%$ ) were prepared, and electrophoresis was performed as previously described (Griffin et al., 1978). The gels were then fixed and stained with Coomassie blue, destained, impregnated with Enhance (New England Nuclear), and dried onto filter paper. The dried gels were placed in close contact to sheets of "flashed" Kodak Xomat RP film and stored at $-70^{\circ} \mathrm{C}$ (Laskey and Mills, 1975). After 2 to 8 weeks the films were developed to produce gel fluorograms.

To determine the distribution of individual slow component proteins along the nerve, specific bands were cut out of each tract, dissolved in $30 \%$ hydrogen peroxide, and counted in Ultrafluor. The proteins analyzed in this fashion include the 68,000-, 145,000-, and 200,000-dalton neurofilament proteins, tubulin ( 55,000 daltons), actin, clathrin, and a protein of 115,000 daltons referred to as the "SCb marker" protein. This protein was chosen because of its relative prominence in both the front and the tail of $\mathrm{SCb}$; previous studies have demonstrated that the $\mathrm{SCb}$ proteins are transported in a relatively coherent fashion (Garner and Lasek, 1981).

Meaningful comparison of the kinetics of slow trans- 



Figure 1. Fluorograms of polyacrylamide slab gels showing the slow component of axonal transport in sciatic motor nerve fibers 12 days after intraspinal injection of $\left.{ }^{[5} \mathrm{S}\right]$ methionine into 5 -week-old rats. $A$, normal; $B$, DMHD; $C$, IDPN. Each track represents a 3-mm nerve segment, with the most proximal to the left. Note that in the normal nerve the neurofilament triplet 




Figure 2. Fluorograms allowing segment-by-segm at comparison of the slow component in a DMHD and a control animal 12 days after labeling. Each pair of tracks represents somparable $f \mathrm{~mm}$ nerve segments of a DMHD and a control animal, as indicated. The distribution of proteins along the ne re is differe ; for example, the 145,000-dalton protein is most prominent between 0 and $12 \mathrm{~mm}$ in the DMHD tracks and betw en 12 and $i \mathrm{~mm}$ in the control tracks. This gel demonstrates to advantage the identical electrophoretic mobilities of the slow cc uponent $\mathrm{p}$,teins, in spite of their differing distribution in the nerve. Note that the SCb proteins, including the 70,000-dalton $\leqslant$ خb protej and the SCb marker protein ( $\star$ ), are found in more proximal segments in the DMHD tracks than in the control 1 acks. ( $T$ e 200,000-dalton neurofilament protein is not well seen in this gel.)

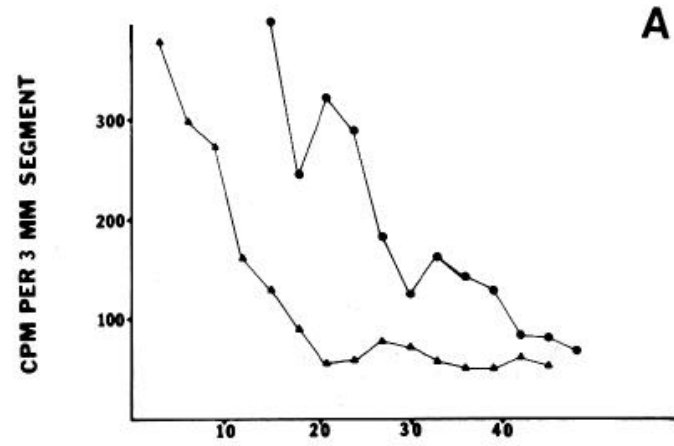

A

B

POSITION ALONG NERVE(MM)

Figure 3. Comparison of the location of the front of SCb in control ( ) and DMHD (A) nerves removed 2 days after labeling. These animals had comparable amounts of radioactivity, allowing direct comparison. $A$, Tubulin ( 53,000 to 56,000 daltons). $B$, $\mathrm{SCb}$ marker protein $(115,000$ daltons). Note that for both proteins the front is somewhat more distal in the normal nerve. These rapidly moving fronts represent a small proportion of total $\mathrm{SCb}$ radioactivity; most of the radioactivity in $\mathrm{SCb}$ moves at rates of 2 to $3 \mathrm{~mm} /$ day and remains within the spinal cord or proximal root at this very early time.

proteins $(200,000,145,000$, and 68,000 daltons) are found 3 to $24 \mathrm{~mm}$ along the nerve; this region represents SCa of Lasek and Hoffman (1976). In both experimental animals the neurofilament 145,000- and 200,000-dalton proteins are difficult to identify and certainly do not extend beyond $6 \mathrm{~mm}$. (In all nerves a protein near the 68,000 -dalton neurofilament protein in molecular weight extends well down the nerve; this protein is of slightly higher molecular weight, as seen in Fig. 2). Note also that all slow component proteins are mildly retarded in the experimental animals, including clathrin (*), the SCb marker protein (see the text) $(\star)$, actin $(45)$, and tubulin $(55)$. 
port following experimental manipulation is complicated by the normal reduction in velocity of the slow component with age (Black and Lasek, 1979; Komiya, 1980; Hoffman et al., 1983) and by the fact that in rat sciatic motor nerves the slow component spreads, slows, and becomes more complex in pattern with passage down the nerve (Hoffman et al., 1983). The most satisfactory approach to this problem was to express the distribution of specific proteins along nerves in terms of their "halfvelocity," comparing animals of similar age and postlabeling intervals. Cumulative plots of the amount of radioactivity per segment of nerve for each protein of interest were drawn (see illustration in Fig. $5, B$ and $D$ ). The half-velocities were defined as the distance in millimetcrs reached by half the radioactivity in a specific protein, divided by the time after labeling in days. When possible, postlabeling intervals were chosen so that the radioactivity associated with a specific protein was within the length of nerve available (i.e., radioactivity was not still entering the nerve proximally nor extending beyond the most distal segments available). Estimates of half-velocities undoubtedly overestimate the rate of neurofilament transport after IDPN or DMHD intoxication, because with both agents the neurofilament proteins were still entering the ventral roots at the intervals chosen. In such situations the differences from control must be considered minimum estimates.

\section{Tissue fixation and preparation}

For morphological comparison, rats were anesthetized with chloral hydrate and were perfused through the ascending aorta with $5 \%$ glutaraldehyde in $0.1 \mathrm{M}$ sodium phosphate buffer ( $\mathrm{pH}$ 7.3). The lumbar ventral horns and proximal ventral roots were osmicated, embedded in Epon-Araldite, sectioned at $1 \mu \mathrm{m}$, and stained with toluidine blue.

\section{Results}

Control nerve. Both the distribution of total radioactivity (as determined from aliquots) and the gel fluorograms reproduced the extensively described features of normal slow transport (Hoffman and Lasek, 1975; Black and Lasek 1980; Garner and Lasek 1981). A slow moving peak of radioactivity (SCa of Lasek and Hoffman, 1976) was preceded by a more rapidly moving component $(\mathrm{SCb}$ of Lasek and Hoffman) whose front gradually merged into base line or background levels of radioactivity.

On the basis of gel fluorograms, $\mathrm{SCa}$ can be defined as the region containing the neurofilament triplet proteins $(68,000,145,000$, and 200,000 daltons) (Lasek and Hoffman, 1976) (Figs. $1 A$ and 2). The 145,000 -dalton neurofilament protein ( $\mathrm{nf}$ 145) was used for half-velocity analysis. (The 68,000-dalton protein (nf 68) was preceded by a more rapidly moving protein with a slightly greater molecular weight ( 70,000 daltons). These proteins can be distinguished on gel fluorograms but cannot be distinguished in gel slice counts, thereby making determination of the half-velocities for $\mathrm{nf} 68$ somewhat less accurate than for $n f$ 145.) The most heavily labeled protein in the $\mathrm{SCa}$ region was tubulin, seen in this gel system as a single band at 55,000 daltons. The half-velocities for transport of $\mathrm{nf} 145$ and tubulin in normal animals of the ages and postlabeling intervals relevant to this study are shown in Figure 6.

The $\mathrm{SCb}$ region contained a more complex collection of proteins as previously described (Black and Lasek, 1980; Garner and Lasek, 1981). These included the SCb marker protein (115,000 daltons) described under "Materials and Methods," as well as actin and some tubulin (Hoffman and Iasek, 1980). At 2 days after labeling, SCb proteins were found up to $40 \mathrm{~mm}$ along the nerve (Fig. 3). These proteins include small amounts of protein co-migrating with tubulin, as well as clathrin and the $\mathrm{SCb}$ marker protein. However, the amount of radiolabel associated with these very rapidly moving $\mathrm{SCb}$ proteins was small; most of the radioactivity in SCb proteins moved 2 to $3 \mathrm{~mm} /$ day (Fig. 4), so that calculating halfvelocities for longer postlabeling intervals (e.g., 12 days) produced only minor underestimations of the rates for tubulin and the $\mathrm{SCb}$ marker protein transport.

$D M H D$. The outstanding abnormality produced by DMHD administration was impairment of transport of neurofilament proteins. In four 5 -week-old animals (12 days after labeling) half-velocities for $\mathrm{nf} 145$ averaged $<0.6 \mathrm{~mm}$ /day (Figs. 2, 5B, and 6). The designation $<0.6$ $\mathrm{mm} /$ day is given because the measured value of $0.6 \mathrm{~mm} /$ day undoubtedly overestimated the rate of transport of nf 145 protein; at 12 days an undefined proportion of labeled neurofilaments had not yet entered the anterior roots, as noted above. The least severely affected animal (Figs. 2 and 5) had labeled neurofilament proteins extending more than $12 \mathrm{~mm}$ into the nerve. In the more severely affected animals, the 145,000-dalton protein could not be seen beyond the first 3-mm segment of the nerve (Fig. $1 B$ ). At 21 days after labeling, the peak of neurofilament proteins again occupied a much more proximal location than in normal animals (half-velocity 0.78 compared to 2.38 in control animals).

Tubulin half-velocities were mildly but consistently reduced following DMHD administration (Figs. $5 D$ and 6). Inspection of the fluorograms showed a similar mild retardation of transport of the SCb proteins (compare the distribution of clathrin and the $\mathrm{SCb}$ marker protein in Fig. 1, $A$ and $B$ and in experimental and control tracts in Fig. 2). This retardation also affected the front of $\mathrm{SCb}$ as seen 2 and 4 days after labeling (Fig. 3). The quantitative measurements of retardation of SCb (Figs. 4 and 6) confirmed the visual impression that these changes were mild compared to the changes in neurofilament proteins.

DMHD administration produced neither elimination of labeled proteins from the slow component nor the appearance of new labeled proteins not present in the control animals (Fig. 2). The relative abundance of label in the slow component proteins also appeared comparable; in particular, the ratios of radioactivity in the individual neurofilament proteins to each other and to tubulin remained normal. Finally, careful inspection of the electrophoretic mobilities of individual proteins showed no detectible differences between DMHD and control nerves (Fig. 2).

$I D P N$. The IDPN-treated animals reproduced almost exactly the pattern of changes seen with DMHD, although the abnormalities in the IDPN group were more 


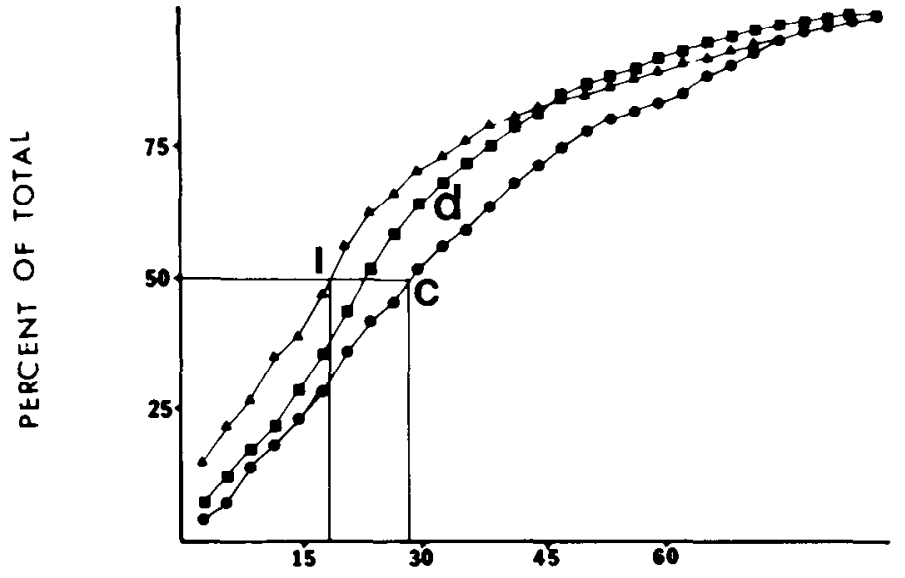

POSITION ALONG NERVE (MM)

Figure 4. Cumulative plots of radioactivity in the $\mathrm{SCb}$ marker protein 12 days after labeling, comparing normal (c), DMHD $(d)$, and IDPN $(i)$ animals 12 days after labeling. These plots were obtained by calculating for each segment the percentage of total radioactivity in the $\mathrm{SCb}$ marker protein in the whole nerve. The results were then plotted in a cumulative fashion, beginning with the most proximal segment. Fifty percent of the total SCb marker radioactivity is reached at 29,24 , and $19 \mathrm{~mm}$ along the nerve for $c, d$, and $i$, resulting in half-velocities of 2.4 , 2.0 , and $1.6 \mathrm{~mm} /$ day respectively.

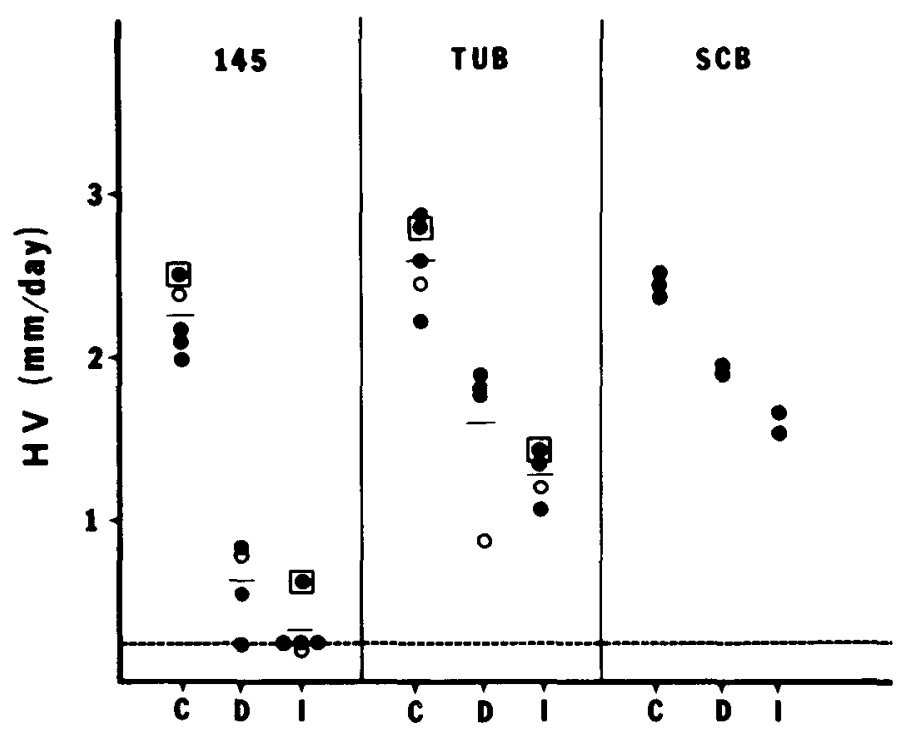

Figure 6. Plot of half-velocities $(H V)$ for the nf 145 , tubulin $(T U B)$ and the $\mathrm{SCb}$ marker protein $(S C b)$. C, control; $D$, DMHD; $I$, IDPN;, 5 -week-old rat 12 days after labeling; $\bigcirc$, 5 -week-old rat 21 days after labeling; $\square, 3$-week-old rat 15 days after labeling.
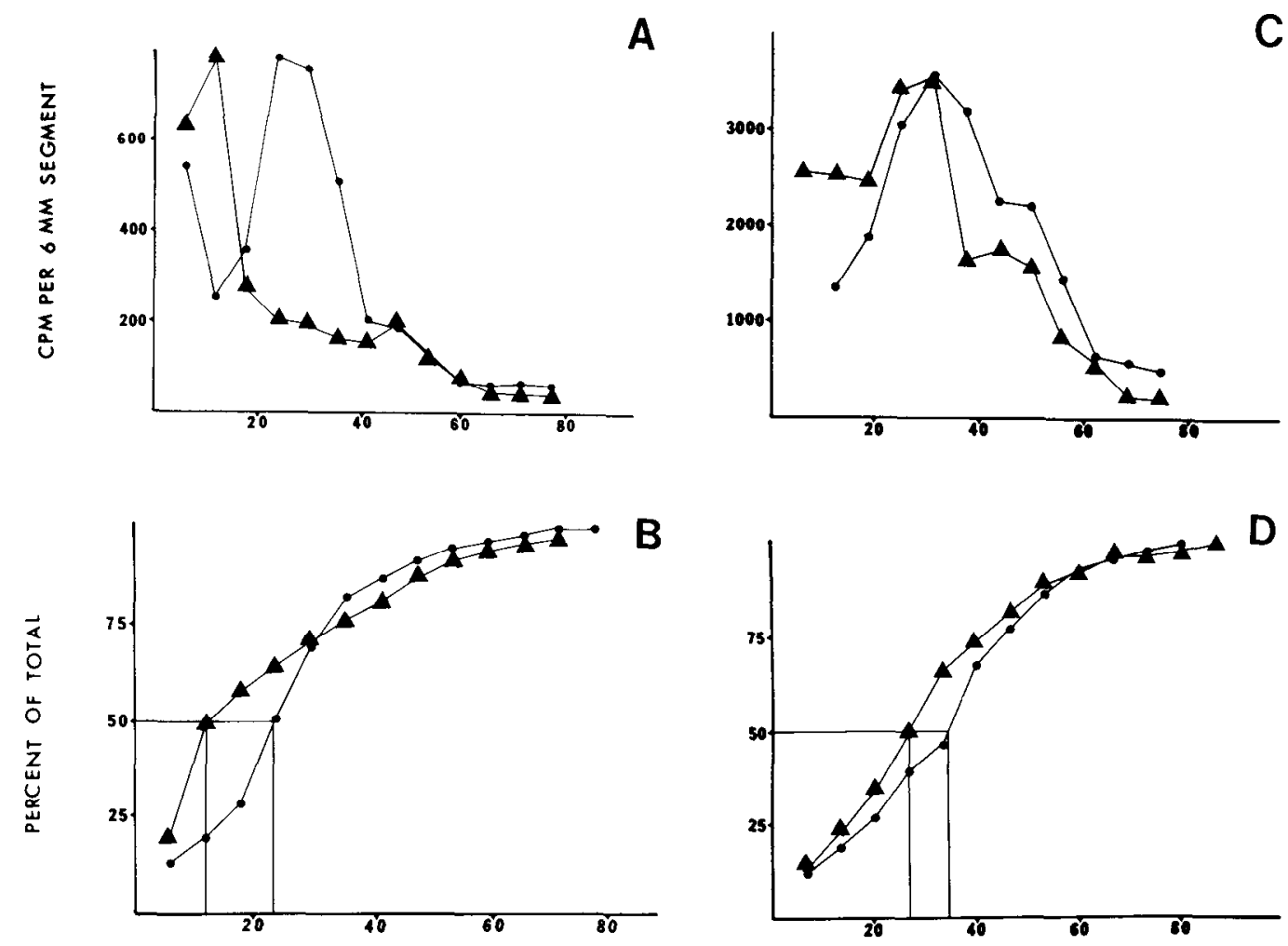

POSITION ALONG NERVE (MM)

Figure 5. Distributions of the nf $145(A$ and $B)$ and of tubulin (55,000 daltons) $(C$ and $D)$ in control (O) and DMHD (A) animals 12 days after labeling. In $A$ and $C$, counts per segment are plotted in these comparably labeled nerves. These plots demonstrate a marked retardation of neurofilament proteins, compared to tubulin, in the DMHD nerve. $B$ and $D$ are cumulative plots of the same data; half-velocities for the neurofilament protein are 2.0 (control) and 0.8 (DMHD), whereas tubulin halfvelocities are 2.9 (control) and 2.3 (DMHD) $\mathrm{mm} /$ day. 
severe, perhaps reflecting the more rapid intoxication schedule with IDPN. In 5-week-old animals (12 days after labeling) neurofilament proteins had not yet entered the nerves from the spinal cords in any of three animals (half-velocities $<0.25 \mathrm{~mm} /$ day) (Figs. $1 C$ and 6 ). The 3-week-old animals provided a group in which the transport of neurofilament proteins could be better studied, because a peak, although markedly retarded, had largely entered the nerve by 15 days. Figure 7 shows that in these nerves the half-velocity for $\mathrm{nf} 145$ was reduced to $0.6 \mathrm{~mm} /$ day compared to $2.5 \mathrm{~mm} /$ day in the control.

Tubulin was moderately affected (Fig. 7); the tubulin half-velocities were reduced to $1.4 \mathrm{~mm} /$ day in the $3-$ week-old IDPN animal and $1.19 \mathrm{~mm} /$ day in the 5 -weekold IDPN animals compared with 2.8 and $2.5 \mathrm{~mm} /$ day, respectively, in the controls (Fig. 6). Inspection of the fluorograms demonstrated retardation of all SCb proteins; quantitation of the $\mathrm{SCb}$ marker protein demonstrated a $36 \%$ reduction in half-velocities at 12 days (Figs. 4 and 6). The reduction in velocity of the $\mathrm{SCb}$ proteins was also apparent in the small front present 2 days after labeling (similar to the findings with DMHD illustrated in Fig. 3).

It should be noted that with both DMHD and IDPN simple radiometric assessment of total counts in slow transport could have missed the defect in neurofilament transport. For example, 12 days after labeling the experimental groups had little neurofilament protein within the nerve, so that plots of total radioactivity misleadingly suggested an acceleration of the slow component.

Pathological findings. At 12 days both DMHD and IDPN produced substantial neurofilamentous swellings in the intraparenchymal motor fibers and proximal ventral roots (sce Fig. 8, $B$ and $C$ ). These observations indicate that the doses were appropriate to produce comparable lesions, although the rate of intoxication was greater for IDPN than for DMHD. The details of the pathological changes in these models have been reported separately (for DMHD, see Anthony et al., 1983a, c; for IDPN, see Chou and Hartmann, 1964, 1965; Clark et al., 1980; Griffin and Price, 1980, 1981; Griffin et al., 1982b).

Clinical findings. There were substantial differences in the behavior of animals exposed to DMHD and IDPN. DMHD produced a rapid flaccid weakness and loss of toe spreading in the hind limbs (Anthony et al., 1983a, c). IDPN produced the hyperactivity and "waltzing" described in previous reports (Chou and Hartmann, 1964), without obvious weakness.

\section{Discussion}

The major finding in this study was the striking similarity in the details of the axonal transport defect pro-


B

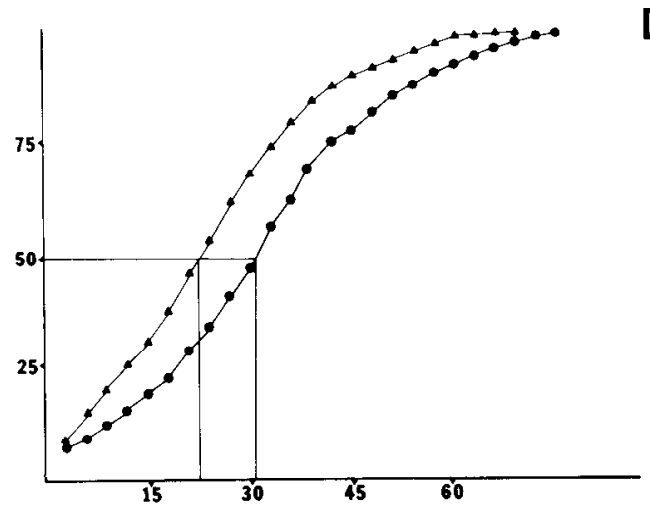

POSITION ALONG NERVE(MM)

Figure 7. Comparison of control (๑) and IDPN $(\boldsymbol{\Delta})$, plotted as described in Figure 5 . These animals were 3 weeks old at the time of labeling, and nerves were removed 15 days later. These animals allowed meaningful comparisons, since most of the neurofilanent proteins and tubulin were in the sciatic nerve at the time of removal. Note the marked retardation of neurofilament transport. 

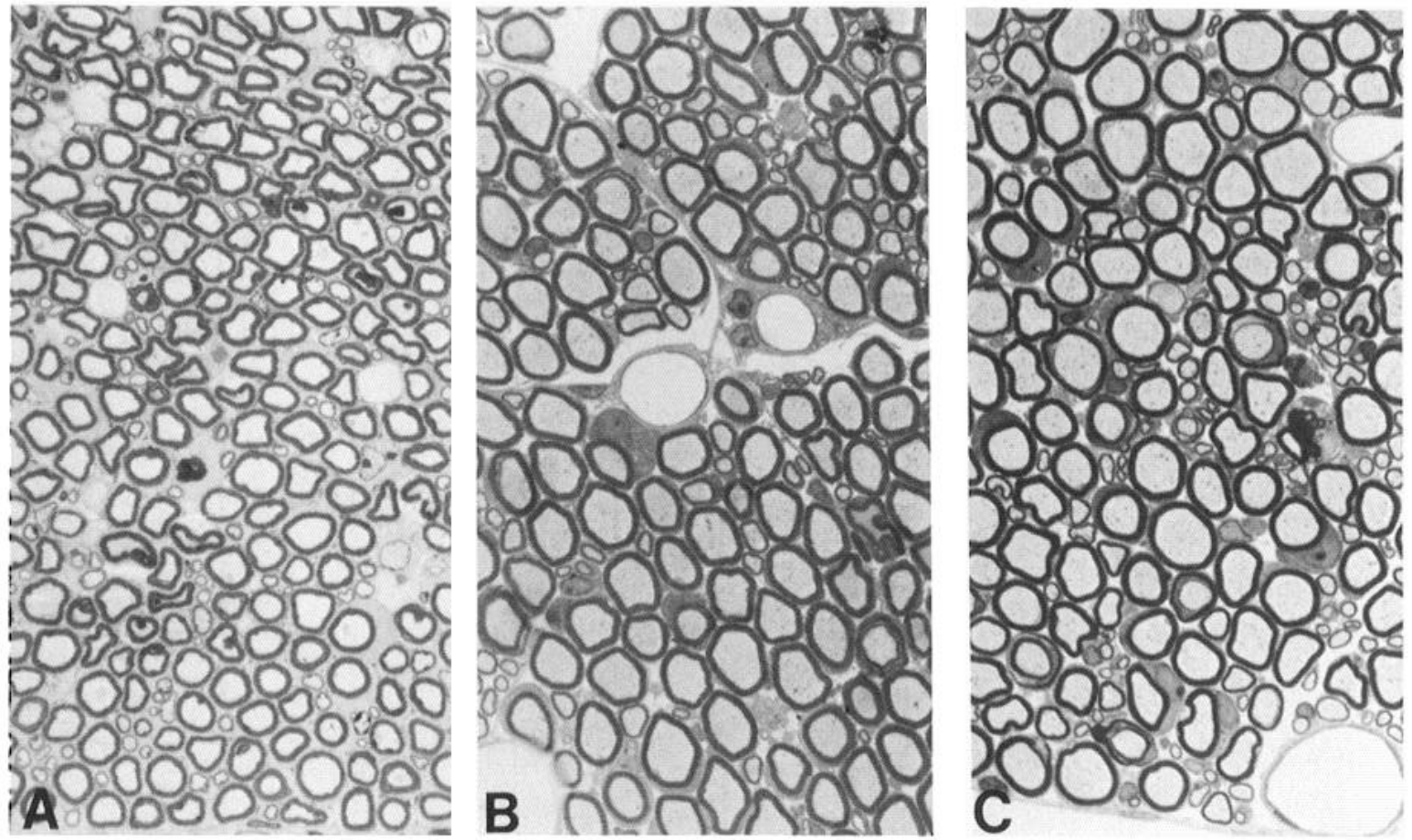

Figure 8. Light micrographs of the proximal ventral roots of control $(A)$, DMHD $(B)$, and IDPN $(C)$ animals. Note the comparable degree of axonal enlargement of the DMHD and IDPN nerves, compared to control. These are 1- $\mu \mathrm{m}$ Epon sections stained with toluidine blue. All magnifications $\times 575$.

duced by DMHD and IDPN. With both agents neurofilament transport was most severely affected, but even at early times there was also evidence of abnormalities in transport of tubulin and $\mathrm{SCb}$ proteins. The relative magnitude of the defect in neurofilament transport can be gauged from the fact that in both DMHD and IDPN intoxication the half-velocities of the 145,000-dalton protein were reduced by 75 to $90 \%$ from control values. In contrast, tubulin and the $\mathrm{SCb}$ marker proteins were slowed by only 20 to $50 \%$. The morphological alterations associated with the transport defect were also strikingly similar. These results suggest that shared, if not identical, pathogenetic processes are involved.

Previous studies showed that IDPN administration affects profoundly the intra-axonal movement of neurofilament proteins within the slow phase of axonal transport (Griffin et al., 1978; Yokoyama et al., 1980) while producing slight or no abnormalities of fast axonal transport (Griffin et al., 1978, 1982a; Papasozomenos et al., 1982). This neurofilament transport defect is associated with a morphological reorganization of the axonal cytoskeleton in which the neurofilaments become dissociated from microtubules and form a subaxolemmal ring, while the microtubules are congregated in the center of affected axons (Papasozomenos et al., 1981, 1982; Griffin et al., 1983b). EM autoradiographic studies have shown that fast axonal transport continues to pass unimpeded within the microtubule "channels" (Papasozomenos et al., 1982; Griffin et al., 1983b). IDPN appears to affect the axon directly, since the characteristic cytoskeletal changes can be produced by local injection of the agent into the endoneurial space of peripheral nerves (Griffin et al., 1983b). These observations have led to the hypothesis that IDPN or one of its metabolites interacts with some axonal factor responsible for normal organization of the cytoskeleton, producing segregation of neurofilaments and preventing their continued translocation proximal-to-distal down the axon. The cell body continues to synthesize neurofilaments, but the abnormalities in transport result in regions of neurofilament accumulation, usually in the proximal portions of large fibers (Chou and Hartmann, 1964, 1965; Griffin and Price, 1980).

An outstanding question has been whether this sequence is an isolated experimental curiosity confined to a single model, or whether it has more general applicability in neurofibrillary disorders. The conclusion drawn from the present study is that DMHD and IDPN share pathogenetic mechanisms, and indirect evidence suggests that HD has similar, but less severe, effects. When injected directly into rat sciatic nerves, HD has reproduced the cytoskeleton disorganization associated with IDPN administration (Griffin et al., 1983a). The differences in the usual distribution of the pathological changes (IDPN proximal, HD distal) do not reflect basic differences in mechanisms, since IDPN can also produce distal axonal swellings (Griffin et al., 1982b) and HD can produce more widespread swellings (Cavanagh and Bennetts, 1981; Cavanagh, 1982). The similarity in the swellings produced by HD and IDPN is underlined by the fact that in both models the swellings can migrate distally down the nerve if toxic exposure is discontinued (Shimono et al., 1978; Griffin and Price, 1981; Cavanagh, 1982). It seems likely that the distribution of lesions is dictated by the potency and administration schedule of the agent, as suggested by Graham et al. (1982b) and Anthony et al. (1983a, b, c). The lower potency of HD may require that neurofilaments be continuously exposed 
to the agent as they are transported down the axon to culminate in sufficient cytoskeleton disorganization to produce neurofilamentous masses.

With the striking similarities between DMHD and IDPN, significant differences remain to be explained. First, the DMHD animals rapidly become weak, and previous studies have described extensive distal nerve fiber degeneration and loss within days (Anthony et al., $1983 \mathrm{a}, \mathrm{c}$ ). IDPN produces less evidence of weakness and fiber degeneration, but instead results in the syndrome of "waltzing," circling, retropulsion, and rotatory head movements (Chou and Hartmann, 1964). The bases for these differences remain unknown; future studies should determine whether DMHD more severely affects fast transport, which in turn contributes to Wallerian-like degeneration.

The results point up some of the difficulties in comparing normal and abnormal axonal transport and in quantitation of slow transport. Expressing results exclusively in terms of the rate of movement of a peak of slow transport is often unsatisfactory, as is apparent from inspection of Figure 3. The fronts of both $\mathrm{SCa}$ and $\mathrm{SCb}$ are normally poorly defined; although an apparent front of $\mathrm{SCh}$ moving 3 to $4 \mathrm{~mm} /$ day is often seen, some $\mathrm{SCb}$ constituents move at least $20 \mathrm{~mm} /$ day (Fig. 3). Cumulative plots and half-velocities, as used in this report, provide advantages, but the limitations of these conventions must be kept in mind. Meaningful comparisons require animals of the same age and duration after labeling (Hoffman et al., 1983). A postlabeling interval at which all of the transported label in a protein of interest lies within the available length of control nerves may not be optimal for nerves with altered transport. For example, 12 days after labeling, all of the label in $\mathrm{nf} 145$ is within the nerve in normal animals, but in DMHD- and IDPN-treated animals only a small proportion of the labeled nf 145 has entered the nerve. Measurements of half-velocity in this situation overestimate the rate of transport. Similarly, if some of the labeled protein had migrated beyond the available length of nerve, the halfvelocity would underestimate the true rate. The difficulties are greater in attempting to quantitate $\mathrm{SCb}$ transport. Many $\mathrm{SCb}$ proteins do not form a transport wave but, rather, a relatively flat "plateau" of radioactivity corresponding to rates of 1 to $4 \mathrm{~mm} /$ day (Fig. $1 A$ ), preceded by the low level of radioactivity extending up to $20 \mathrm{~mm} /$ day (Fig. 2). Thus, even though a substantial proportion of the SCb marker protein is moving at much more rapid rates than the $\mathrm{SCa}$ proteins, the half-velocity is only slightly greater (see Fig. 6) and provides a measure of only limited value. For SCb proteins, inspection of the fluorograms (Fig. 1) and the cumulative plots at multiple postlabeling intervals provides a useful means of comparing transport in normal and experimental situations.

DMHD promises to be a useful tool in assessing the biological basis for the defects in organization and translocation of the cytoskeleton. A major limitation of IDPN as a probe has been the uncertainty concel riing whether it undergoes biotransformation to a neurotoxic metabolite. DMHD is an analogue of the proven neurotoxin 2,5$\mathrm{HD}$ and was predicted to be a more potent neurotoxin, based on the hypothesis that $\gamma$-diketones interact with 6-amino groups of proteins to form pyrrole rings (DeCaprio et al., 1982; Graham et al., 1982a, b; Anthony et al., 1983a, b, c). DMHD cyclizes with amines more rapidly than $2,5-\mathrm{HD}$ and formation of pyrrolyl derivatives of proteins has been demonstrated in vitro and in vivo. Previous studies have demonstrated that DHMD provides a 20 - to 40 -fold increase in potency over 2,5-HD (Anthony et al., 1983b). The more proximal distribution of pathology produced by DMHD presumably reflects its greater neurotoxic efficacy.

The precise means by which these agents impair translocation of neurofilaments is uncertain, but it is likely to result from the disorganization of the axonal cytoskeleton, with segregation of neurofilaments from microtubules (Papasozomenos et al., 1982; Griffin et al., 1983a, b). Recent studies of 2,5-HD have suggested that a similar defect in integration of intermediate filaments in non-neural cells occurs. Powell et al. (1978) noted neurofilamentous masses in Schwann cells of rats exposed to 2,5-HD, and Durham and Pena (1982) have recently found spherical intermediate filament masses in fibroblasts grown with 2,5-HD in the media. Graham et al. $(1982 a, b)$ and Anthony et al. (1983a, b, c) have suggested that covalent cross-linking of neurofilament proteins could be the event which leads to segregation of neurofilaments from microtubules. Such covalent cross-linking has been postulated to occur in a two-stage sequence: initial formation of pyrrole rings on neurofilaments as described above, followed by oxidation of the pyrroles with subsequent nucleophilic attack and covalent bond formation (Graham et al., 1982a, b; Anthony et al., 1983a, $\mathrm{b}, \mathrm{c})$. In this regard, the tetramethylpyrrole formed by reaction between lysyl residues and DMHD is oxidized more rapidly than that dimethylpyrrole formed by HD. This factor, along with the greater rate of pyrrole formation, might explain the greater potency of DMHD. An alternative proposal for the neurotoxicity of DMHD and HD is the possibility that pyrrole ring formation in itself impairs normal interactions between neurofilaments and their cross-linkers, resulting in an inability to integrate neurofilaments normally into the cytoskeleton and to continue proximal-to-distal transport. Finally, inhibition of the enzymes glyceraldehyde-3-phosphate dehydrogenase (Sabri et al., 1979) and neuron-specific enolase (Howland et al., 1980), previously demonstrated for $\mathrm{HD}$, has also been suggested as a pathogenetically important effect.

The present results indicate that similar defects in slow transport are present in two types of neurofilamentous axonopathies. The extent to which such defects might occur in other disorders, particularly those characterized by perikaryal neurofilament accumulations, is beginning to be explored (Bizzi et al., 1983; Troncoso et al., 1984).

\section{References}

Allen, N. (1980) Identification of methyl $n$-butyl ketone as the causative agent. In Experimental and Clinical Neurotoxicology, P. S. Spencer and H. H. Schaumburg, eds., pp. 834-845, Williams \& Wilkins, Baltimore.

Anthony, D. C., K. Boekelheide, and D. G. Graham (1983a) The effect of 3,4-dimethyl substitution on the neurotoxicity 
of 2,5-hexanedione. I. Accelerated clinical neuropathy is accompanied by more proximal swellings. Toxicol. Appl. Pharmacol. 71: 362-371.

Anthony, D. C., K. Boekelheide, C. W. Anderson, and D. G. Graham (1983b) The effect of 3,4-dimethyl substitution on the neurotoxicity of 2,5-hexanedione. II. Dimethyl substitution accelerates pyrrole formation and protein crosslinking. Toxicol. Appl. Pharmacol. 71: 372-382.

Anthony, D. C., F. Giangaspero, and D. G. Graham (1983c) The spatio-temporal pattern of the axonopathy associated with the neurotoxicity of 3,4-dimethyl-2,5-hexanedione in the rat. J. Neuropathol. Exp. Neurol. 42: 548-560.

Bizzi, A., R. Crane, M. Yoon, L. Autilio-Gambetti, and P. Gambetti (1983) The axonal transport of neurofilaments is impaired in aluminum intoxication. Neuropathol. Exp. Neurol. $42: 331$.

Black, M. M., and R. J. Lasek (1979) Slowing of the rate of axonal regeneration during growth and maturation. Exp. Neurul. 63: 108-119.

Black, M. M., and R. J. Lasek (1980) Slow components of axonal transport: Two cytoskeletal networks. J. Cell Biol. 86: 616-623.

Cavanagh, J. B. (1982) The pattern of recovery of axons in the nervous system of rats following 2,5-hexanediol intoxication: A question of rheology? Neuropathol. Appl. Neurobiol. 8: 1934.

Cavanagh, J. B., and R. J. Bennetts (1981) On the pattern of changes in the rat nervous system produced by 2,5 -hexanediol. Brain 104: 297-318.

Chou, S.-M., and H. A. Hartmann (1964) Axonal lesions and waltzing syndrome after IDPN administration in rats. With a concept-“axostasis." Acta Neuropathol. 3: 428-450.

Chou, S.-M., and H. A. Hartmann (1965) Electron microscopy of focal ncuroaxonal lesions produced by $\beta, \beta^{\prime}$-iminodipropionitrile (IDPN) in rats. Acta Neuropathol, 4: 590-603.

Clark, A. W., J. W. Griffin, and D. L. Price (1980) The axonal pathology in chronic IDPN intoxication. J Neuropathol. Exp. Neurol. 39: 42-55.

DeCaprio, A. P., P. Weber, and E. S. Olajos (1982) Covalent binding of a neurotoxic $n$-hexane metabolite: Conversion of primary amino to substituted pyrrole adducts by 2,5 -hexanedione. 'Toxicol. Appl. Pharmacol. 65: 440-445.

DiVincenzo, G. D., C. J. Kaplan, and J. Dedinas (1976) Characterization of the metabolites of methyl $n$-butyl ketone, methyl iso-butyl ketone, and methyl ethyl ketone in guinea pig serum and their clearance. Toxicol. Appl. Pharmacol. 36: 511.

Durham, H. D., and S. D. J. Pena (1982) The neurotoxin 2,5hexanedione induces aggregation of intermediate filaments in cultured human skin fibroblasts. Neurology 32: A215.

Garner, J. A., and R. J. Lasek (1981) Clathrin is axonally transported as part of slow component $b$ : The microfilament complex. J. Cell Biol. 88: 172-178.

Graham, D. G., D. C. Anthony, and K. Boekelheide (1982a) In vitro and in vivo studies of the molecular pathogenesis of $n$ hexane neuropathy. Neurobehav. Toxicol. Teratol. 4: 629634.

Graham, D. G., D. C. Anthony, K. Boekelheide, N. A. Maschmann, R. G. Richards, J. W. Wolfram, and B. R. Shaw (1982b) Studies of the molecular pathogenesis of hexane neuropathy. II. Evidence that the pyrrole derivatization of lysyl residues leads to protein crosslinking. Toxicol. Appl. Pharmacol. 64: 415-422.

Griffin, J. W. (1981) Hexacarbon neurotoxicity. Neurobehav. Toxicol. Teratol. 3: 437-444.

Griffin, J. W., and D. L. Price (1980) Proximal axonopathies induced by toxic chemicals. In Experimental and Clinical Neurotoxicology, P. S. Spencer and H. H. Schaumburg, eds., pp. 161-178, Williams \& Wilkins, Baltimore.
Griffin, J. W., and D. L. Price (1981) Demyelination in experimental IDPN and hexacarbon neuropathies: Evidence for an axonal influence. Lab. Invest. 45: 130-141.

Griffin, J. W., D. B. Drachman, and D. L. Price (1976) Fast axonal transport in motor nerve regeneration. J. Neurobiol. 7: $355-370$.

Griffin, J. W., P. N. Hoffman, A. W. Clark, P. 'T. Carroll, and D. L. Price (1978) Slow axonal transport of neurofilament proteins: Impairment by $\beta, \beta^{\prime}$-iminodipropionitrile administration. Science 202: 633-635.

Griffin, J. W., D. L. Price, D. B. Drachman, and J. R. Morris (1981) Incorporation of axonally transported glycoproteins into axolemma during nerve regeneration. J. Cell Biol. 88 : 205-214.

Griffin, J. W., P. N. Hoffman, and D. L. Price (1982a) Axonal transport in $\beta, \beta^{\prime}$-iminodipropionitrile neuropathy. In $A x_{0}$ plasmic Transport in Physiology and Pathology, D. G. Weiss and A. Gorio, eds., pp. 109-118, Springer-Verlag, Berlin.

Griffin, J. W., B. G. Gold, L. C. Cork, D. L. Price, and II. E. Lowndes (1982b) IDPN neuropathy in the cat: Coexistence of proximal and distal axonal swellings. Neuropathol. Appl. Neurobiol. 8: 351-364.

Griffin, J. W., K. E. Fahnestock, D. L. Price, and L. C. Cork (1983a) Cytoskeletal disorganization induced by local application of IDPN and 2,5-hexanedione. Ann. Neurol. 14: 5561.

Griffin, J. W., K. E. Fahnestock, D. L. Price, and P. N. Hoffman (1983b) Microtubule-neurofilament segregation produced by $\beta, \beta^{\prime}$-iminodipropionitrile: Evidence for the association of fast axonal transport with microtubules. J. Neurosci. 3: 557-566.

Hoffman, P. N., and R. J. Lasek (1975) The slow component of axonal transport. Identification of major structural polypeptides of the axon and their generality among mammalian neurons. J. Cell Biol. 66: 351-366.

Hoffman, P. N., and R. J. Lasek (1980) Axonal transport of the cytoskeleton in regenerating motor neurons: Constancy and change. Brain Res. 202: 317-333.

Hoffman, P. N., R. J. Lasek, J. W. Griffin, and D. L. Price (1983) Slowing of the axonal transport of neurofilament protein during development. J. Neurosci. 3: 1694-1700.

Howland, R. D., I. L. Vyas, H. E. Lowndes, and T. M. Argeneri (1980) The etiology of toxic peripheral neuropathies: In vitro effects of acrylamide and 2,5-hexanedione on brain enolase and other glycolytic enzymes. Brain Res. 202: 131-142.

Ishii, N., A. Herskowitz, and H. Schaumburg (1972) n-Hexane polyneuropathy: A clinical and experimental study. J. Neuropathol. Exp. Neurol. 31: 198-210.

Komiya, Y. (1980) Slowing with age of the rate of slow axonal flow in bifurcating axons of rat dorsal root ganglion cells. Brain Res. 183: 477-480.

Korobkin, R., A. K. Asbury, A. J. Sumner, and S. L. Nielsen (1975) Glue-sniffing neuropathy. Arch. Neurol. 32: 158-162.

Lasek, R. J., and P. N. Hoffman (1976) The neuronal cytoskeleton, axonal transport and axonal growth. Cold Spring Harbor Conf. Cell Prolif. 3: 1021-1049.

Laskey, R. A., and A. D. Mills (1975) Quantitative film detection of ${ }^{3} \mathrm{H}$ and ${ }^{14} \mathrm{C}$ in polyacrylamide gels by fluorography. Eur. J. Biochem. 56: 335-341.

Mendell, J. R., K. Saida, M. F. Ganansia, D. B. Jackson, H. Weiss, R. W. Gardinier, C. Christman, N. Allen, D. Couri, J. O'Neill, B. Marks, and L. Hetland (1974) Toxic polyneuropathy produced by methyl $n$-butyl ketone. Science 185: 787789.

Papasozomenos, S. Ch., L. Autilio-Gambetti, and P. Gambetti (1981) Reorganization of axoplasmic organelles following $\beta, \beta^{\prime}$-iminodipropionitrile administration. J. Cell Biol. 91: $866-871$.

Papasozomenos, S. Ch., M. Yoon, R. Crane, L. Autilio-Gambetti, and P. Gambetti (1982) Redistribution of proteins of 
fast axonal transport following administration of $\beta, \beta^{\prime}$-iminodipropionitrile: A quantitative autoradiographic study. $\mathrm{J}$. Cell Biol. 95: 672-675.

Powell, H. C., T. Koch, R. R. Garrett, and P. W. Lampert (1978) Schwann cell abnormalities in 2,5-hexanedione neuropathy. J. Neurocytol. 7: 517-528.

Sabri, M. I., C. L. Moore, and P. S. Spencer (1979) Studies on the biochemical basis of distal axonopathies. I. Inhibition of glycolysis by neurotoxic hexacarbon compounds. J. Neurochem. 32: 683-689.

Saida, K., J. R. Mendell, and H. S. Weiss (1976) Peripheral nerve changes induced by methyl $n$-butyl ketone and potentiation by methyl ethyl ketone. J. Neuropathol. Exp. Neurol. 35: $207-225$.

Selkoe, D. J. (1982) Molecular pathology of the aging human brain. Trends Neurosci. 5: 332-336.

Shimono, M., K. Izumi, and Y. Kuroiwa (1978): 3,3'-Iminodipropionitrile induced centrifugal segmental demyelination and onion bulb formation. J. Neuropathol. Exp. Neurol. 37: $375-386$.

Shirabe, T., T. Tsuda, A. Terao, and S. Araki (1974) Toxic polyneuropathy due to glue-sniffing. Report of two cases with a light and electron-microscopic study of the peripheral nerves and muscles. J. Neurol. Sci. 21: 101-113.

Spencer, P. S., and J. W. Griffin (1982) Disruption of axo- plasmic transport by neurotoxic agents. The 2,5-hexanedione model. In Axoplasmic Transport in Physiology and Pathology, D. G. Weiss and A. Gorio, eds., pp. 92-103, Springer-Verlag, Berlin.

Spencer, P. S., and H. H. Schaumburg (1977) Ultrastructural studies of the dying-back process. III. The evolution of experimental peripheral giant axonal degeneration. J. Neuropathol. Exp. Neurol. 36: 276-299.

Spencer, P. S., H. H. Schaumburg, M. I. Sabri, and B. Veronesi (1980) The enlarging view of hexacarbon neurotoxicity. CRC Crit. Rev. Toxicol. 7: 279-356.

Troncoso, J., J. W. Griftin, P. N. Hoffman, K. M. Hess-Kozlow, J. R. Blum, and D. L. Price (1984) Slow axonal transport of neurofilament proteins in aluminum intoxication. Soc. Neurosci. Abstr., in press.

Wisniewski, H. M., and D. Soifer (1979) Neurofibrillary pathology: Current status and research perspectives. Mech. Age. Dev. 9: 119-142.

Wolthius, E., B. Bossenbroek, G. DeWall, E. Geels, and A. Leegwater (1963) Reactions of methyl-substituted 1,4-epoxy1,4-dihydronaphthalenes. J. Org. Chem. 28: 148-153.

Yokoyama, K., S. Tsukita, H. Ishikawa, and M. Kurokawa (1980) Early changes in the neuronal cytoskeleton caused by $\beta, \beta^{\prime}$-iminodipropionitrile: Selective impairment of neurofilament polypeptides. Biomed. Res. 1: 537-547. 